\title{
Massive Urinary Protein Excretion Associated with Greater Neonatal Risk in Preeclampsia
}

Julio Mateus, MD, PhD ${ }^{1}$ Roger Newman, MD $\quad$ Baha M. Sibai, MD² Qing Li, PhD 3 John R. Barton, MD C. Andrew Combs, MD, PhD ${ }^{5}$ Edwin Guzman, MD ${ }^{6}$ Kim A. Boggess, MD ${ }^{7}$ Cynthia Gyamfi, MD, MSC ${ }^{8}$ Peter von Dadelszen, MBChB, DPhil ${ }^{9}$ Doug Woelkers, MD ${ }^{10}$

${ }^{1}$ Division of Maternal-Fetal Medicine, Department of Obstetrics and Gynecology, Medical University of South Carolina, Charleston, South Carolina

2 Department of Obstetrics and Gynecology, University of Texas Health Science Center at Houston, Houston, Texas

${ }^{3}$ Center of Behavioral Epidemiology and Community Health (CBEACH), San Diego State University, San Diego, California

${ }^{4}$ Department of Obstetrics and Gynecology, Central Baptist Hospital, Lexington, Kentucky

${ }^{5}$ Mednax/Obstetrix Medical Group, Campbell, California

${ }^{6}$ Department of Obstetrics and Gynecology, Saint Peter's University Hospital, New Brunswick, New Jersey

${ }^{7}$ Division of Maternal-Fetal Medicine, Department of Obstetrics and Gynecology, University of North Carolina, Chapel Hill, North Carolina

${ }^{8}$ Division of Maternal-Fetal Medicine, Department of Obstetrics and Gynecology, Columbia University Medical Center, New York

${ }^{9}$ Department of Obstetrics and Gynaecology, St Geroge's, University of London, London, United Kingdom,

10 Department of Reproductive Medicine, University of California San Diego, La Jolla, California
Address for correspondence Julio Mateus, MD, PhD, Medical University of South Carolina, 96 Jonathan Lucas Street, Suite 634, MSC 619 Charleston, SC 29425-2503 (e-mail: mateusan@musc.edu).

Am J Perinatol Rep 2017;7:e49-e58.

\begin{abstract}
Keywords

- proteinuria

- PETRA study

- preeclampsia

- complications

- preterm delivery

Objective The objective of this study was to compare clinical outcomes of preeclamptic pregnancies according to the proteinuria level.

Study Design Secondary analysis of a multicenter prospective cohort study of women with preeclampsia (PE) symptomatology. Nonproteinuria, mild-proteinuria, and massive-proteinuria PEs were defined as: $<165 \mathrm{mg}$ in 12 hours or $<300 \mathrm{mg}$ in 24 hours, $165 \mathrm{mg}$ to $2.69 \mathrm{~g}$ in 12 hours or $300 \mathrm{mg}$ to $4.99 \mathrm{~g}$ in 24 hours, and $\geq 2.7 \mathrm{~g}$ in 12 hours or $\geq 5.0 \mathrm{~g}$ in 24 hours, respectively. Individual and composite maternal, fetal, and neonatal outcomes were compared among the PE groups.

Results Of the 406 analyzed pregnancies, 36 (8.8\%) had massive-proteinuria PE, 268 (66.0\%) mild-proteinuria PE, and 102 (25.1\%) nonproteinuria PE. Compared with the other groups, massive-proteinuria PEwomen had significantly higher blood pressures $(p<0.001)$, epigastric pain $(p=0.007)$, and uric acid serum levels $(p<0.001)$ prior to delivery. Composite maternal morbidity was similar across the groups. Delivery $<34^{0 / 7}$ weeks occurred in 80.6, 49.3, and $22.5 \%$ of massive-proteinuria, mild-proteinuria, and nonproteinuria PE groups, respectively $(p<0.0001)$. Composite adverse neonatal outcomes were significantly higher in the massiveproteinuria PE compared with the other groups $(p=0.001)$.

Conclusion While potentially not important diagnostically, massive proteinuria is associated with more severe clinical manifestations of PE prompting earlier delivery.
\end{abstract}

received

October 25, 2016

accepted after revision

February 9, 2017
DOI http://dx.doi.org/ $10.1055 / \mathrm{s}-0037-1601866$. ISSN 2157-6998.
Copyright $\odot 2017$ by Thieme Medical Publishers, Inc., 333 Seventh Avenue, New York, NY 10001, USA. Tel: +1(212) 584-4662.

\section{License terms}

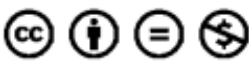


Preeclampsia (PE) affects approximately 3 to $5 \%$ of the pregnant population and is a leading cause of maternal and perinatal morbidity and mortality. ${ }^{1}$ One-quarter of medically indicated preterm deliveries are linked to PE. ${ }^{2}$ In the past decades, a progressively increasing prevalence of PE has been attributed to multiple risk factors including a significant rise in maternal obesity and diabetes, ${ }^{3-5}$ delayed childbearing and to an increased rate of multiple gestations. ${ }^{6}$ Women who develop PE are at significant risk of early cardiovascular disease, hypertension, cerebrovascular accidents, and death. ${ }^{7-9}$ Furthermore, there is growing evidence that offspring born to preeclamptic women are at increased risk for early onset of cardiovascular disease and stroke during adulthood. ${ }^{10,11}$ That risk seems to be more substantial when PE is diagnosed before 34 weeks of gestation. ${ }^{11}$

In 2002, the American College of Obstetricians and Gynecologists (ACOG) practice bulletin ${ }^{12}$ recommended following the diagnostic criteria of PE established by the National High Blood Pressure Education Program Working Group in $2000 .^{13}$ This group defined PE as new onset of hypertension: systolic blood pressure (SBP) $\geq 140 \mathrm{~mm} \mathrm{Hg}$ or diastolic BP (DBP) $\geq 90 \mathrm{~mm} \mathrm{Hg}$ after 20 weeks in a previously normotensive woman and proteinuria along with a protein excretion of $\geq 0.3 \mathrm{~g}$ in a 24 -hour period. ${ }^{13}$ Women with proteinuria $\geq 5 \mathrm{~g}$ in a 24 -hour specimen or $\geq 3+$ on two random urine samples collected at least 4 hours apart met criteria for severe disease by the 2002 ACOG criteria. ${ }^{12}$ In 2013, ACOG published new recommendations on hypertension in pregnancy elaborated by a multidisciplinary panel of experts. ${ }^{14}$ Important changes to the PE definition were made including elimination of the severe PE diagnosis in pregnancies with gestational hypertension and a proteinuria level of $\geq 5 \mathrm{~g}$ in 24 hours. $^{14}$ The rationale behind this new definition was convincing evidence demonstrating a lack of association between the level of urinary protein (UP) loss and pregnancy outcomes. ${ }^{14}$ According to ACOG, the amount of proteinuria or change in the amount of proteinuria, as isolated factors, does not justify delivery in preeclamptic pregnancies with a gestational age $(\mathrm{GA})<37^{0 / 7}$ weeks. $^{14}$

In the new criteria, ACOG recommends diagnosing PE in the absence of proteinuria when any of several abnormalities are present: thrombocytopenia (platelet count $<100,000 /$ $\mu \mathrm{L}$ ), elevated levels of liver transaminases twice or more above the normal concentrations, elevated serum creatinine $>1.1 \mathrm{mg} / \mathrm{dL}$ or a doubling elevation in absence of other renal disease, pulmonary edema, or new-onset cerebral or visual disturbances. ${ }^{14}$ Furthermore, "severe features of PE" is diagnosed when any of these findings are present or when maternal SBP is $\geq 160 \mathrm{~mm} \mathrm{Hg}$ or $\mathrm{DBP} \geq 110 \mathrm{~mm} \mathrm{Hg}$ on two occasions at least 4 hours apart while the patient is on bed rest. ${ }^{14}$ Maternal/fetal conditions and GA are the most important factors in determining the timing of delivery of women with severe disease. For those pregnancies with stable maternal and fetal conditions and GA $<34^{0 / 7}$ weeks, expectant management that involves daily maternal and fetal surveillance is recommended at medical centers equipped with adequate maternal and neonatal intensive care resources. $^{14}$
The relationship between heavy proteinuria and adverse clinical events in pregnancies complicated by PE has been investigated in multiple studies. ${ }^{15-23}$ Some studies have shown that the level of proteinuria is not associated with adverse maternal ${ }^{15-18,20}$ or perinatal outcomes. ${ }^{15-20}$ However, others have reported that heavy proteinuria increases both maternal and perinatal morbidities including severe hypertension, preterm delivery, cesarean delivery, small for GA (SGA) infants, maternal symptoms, and perinatal mortality rate. ${ }^{21-25}$ These conflicting results likely reflect limitations of previous studies including retrospective design, 15 proteinuria quantification by qualitative dipstick method, ${ }^{16-18}$ performance in single-care settings, ${ }^{17,22,23}$ and inclusion of hypertensive disorders other than PE to examine pregnancy outcomes. ${ }^{19}$ Given the recent revision of the diagnostic criteria for PE, we believe it is appropriate to reconsider the association between the degree of proteinuria with the clinical course and pregnancy outcome of PE.

PE Triage by Rapid Assay (PETRA) of novel biomarkers of placental function and maternal adaptation was a recent multicenter prospective cohort study that enrolled women with any signs or symptoms of PE. The primary objective of this study was to validate the Triage placental growth factor test as an aid in the diagnosis of PE in symptomatic women. Importantly, this study classified PE using the most recent ACOG's clinical criteria. The final diagnosis was adjudicated by a panel of independent experts allowing us to compare pregnancy outcomes between nonproteinuric and proteinuric PEs. The objective of our study was to determine whether preeclamptic pregnancies with massive proteinuria, defined as $>2.7 \mathrm{~g}$ in 12 hours or $>5.0 \mathrm{~g}$ in 24 hours, have worse maternal, fetal, or neonatal outcomes compared with those with mild or nonproteinuria.

\section{Materials and Methods}

We conducted a secondary analysis of the multicenter PETRA prospective cohort study. In PETRA, pregnant women 16 to 45 years of age at $20^{0 / 7}$ to $40^{0 / 7}$ weeks of gestation with signs or symptoms of PE were enrolled at 24 centers in the United States and Canada between June 2010 and July 2012. Patients were excluded if the pregnancy had more than three viable fetuses, active substance abuse, were on dialysis, received blood product transfusion within the previous 48 hours, had known or suspected infection with human immunodeficiency virus, hepatitis C virus, hepatitis B virus, or other infectious hepatitis. We also excluded women with underlying renal disease. This study was approved by the Institutional Review Board at our institution.

Signs or symptoms of PE that warranted initial evaluation were new onset of hypertension defined as SBP $\geq 140 \mathrm{~mm}$ $\mathrm{Hg}$ or $\mathrm{DBP} \geq 90 \mathrm{~mm} \mathrm{Hg}$ or rise of $\mathrm{SBP} \geq 30 \mathrm{~mm} \mathrm{Hg}$ or DBP $\geq 15 \mathrm{~mm}$ Hg from patient's BP baseline; worsening BP in patients with chronic hypertension; proteinuria defined as $\geq 1+$ dipstick, $\geq 0.30 \mathrm{UP} /$ creatinine ratio (UP/CR), or $\geq 300 \mathrm{mg}$ in 24 hours. Symptoms potentially associated with PE included persistent epigastric or right upper abdominal pain, nausea, vomiting, or headaches/visual 
disturbances; excessive weight gain $\geq 5$ pounds per week; laboratory abnormalities such as thrombocytopenia (platelets $<100,000 / \mu \mathrm{L}$ ), aspartate aminotransferase (AST), and alanine transaminase (ALT) twice normal, serum creatinine $>1.1 \mathrm{mg} / \mathrm{dL}$ or having doubled, uric acid $>6.0 \mathrm{mg} / \mathrm{dL}$; unexplained clinical events including oliguria, pulmonary edema, and seizure; fetal growth restriction defined as sonographic estimated fetal weight $(E F W) \leq 10$ th percentile for GA; and suspected fetal/placental hydrops, uterine artery Doppler notching, or placental abruption.

At enrollment, demographic and baseline characteristics such as maternal age, gravity and parity, race, $\geq 30 \mathrm{~kg} / \mathrm{m}^{2}$ body mass index, PE in previous pregnancies, history of lupus, history of antiphospholipid antibody syndrome, and smoking status were recorded. GA was assigned by a certain regular last menstrual period (LMP) confirmed by the earliest ultrasound exam. Estimated date of confinement (EDC) was assigned by the earliest ultrasound in women with irregular menstrual cycles or an uncertain LMP. The earliest ultrasound instead of LMP was used for EDC assignment if discrepancies existed as: \pm 5 days for a first trimester $\left(6^{0}-13^{6}\right.$ weeks) ultrasound, \pm 10 days for an early second trimester $\left(14^{0}-22^{6}\right)$ ultrasound, \pm 14 days for a late second trimester $\left(23^{0}-27^{6}\right)$ ultrasound, and \pm 21 days for a third trimester $\left(28^{0}\right.$ to term) ultrasound. BP was obtained following ACOG's recommendations. ${ }^{12}$ Laboratory evaluations included hematocrit, platelet count, serum creatinine, ALT, AST, lactate dehydrogenase (LDH), and uric acid. Women with proteinuria $\geq 1+$ on dipstick or $U P / C R \geq 0.3 \mathrm{mg} / \mathrm{mg}$ underwent 12-hour or 24-hour urine protein excretion assessment. Patients without criteria for PE at the initial study visit whose diagnosis was again suspected at least 1 week later underwent re-evaluation in the same fashion. Medical management including hospitalization, expectant management, and delivery was determined by the attending physicians and internal protocols of the participating institutions.

Our cohort consisted of women with diagnosis of PE adjudicated by an independent expert panel following the most recent guidelines. ${ }^{14}$ HELLP syndrome was defined as PE plus AST and ALT twice normal, LDH twice normal, and thrombocytopenia (platelets $<100,000 / \mu \mathrm{L}$ ). Preeclamptic pregnancies were classified in three groups according to the degree of proteinuria: (1) nonproteinuria PE was defined as either proteinuria $<165 \mathrm{mg}$ in 12 hours or $<300 \mathrm{mg}$ in 24 hours; (2) mild-proteinuria PE included patients with proteinuria between $165 \mathrm{mg}$ and $2.7 \mathrm{~g}$ in 12 hours or from $300 \mathrm{mg}$ to $4.9 \mathrm{~g}$ in 24 hours; and (3) massive-proteinuria PE criteria were proteinuria $>2.7 \mathrm{~g}$ in 12 hours or $>5.0 \mathrm{~g}$ in 24 hours. We used 12 hours proteinuria cutoff values that have been reported to correlate well with 24 hours urine proteinuria values in previous studies. ${ }^{26,27}$ The highest timed proteinuria value was selected in cases with multiple testing. Maternal demographic and clinical characteristics were compared between the PE groups. BP values, symptomatology, and laboratory parameters within 24 hours of delivery were analyzed in each group. Mode of delivery, timing of delivery, birth weight, Apgar scores, and arterial cord gas values were also analyzed when available. Women with superimposed PE were excluded.

Maternal, fetal, and neonatal outcomes were compared among the PE subgroups categorized by their degree of proteinuria. Composite adverse maternal outcome was defined as the presence of any of the following: acute renal failure, liver hematoma/rupture, acute myocardial infarction, cortical blindness, retinal detachment, cerebrovascular accident, pulmonary edema/adult respiratory distress syndrome, placental abruption, eclampsia, need for third intravenous agent to control BP, disseminated intravascular coagulation, or maternal death. Composite adverse fetal outcome included preterm delivery $<34^{0 / 7}$ weeks or $<37^{0 /}$ 7 weeks, intrauterine growth restriction (IUGR) defined as EFW $<10$ th percentile or $<5$ th percentile by ultrasound exam, or antepartum/intrapartum fetal death. Composite adverse neonatal outcome was defined as any of the following: respiratory distress syndrome (RDS), any grade of intraventricular hemorrhage (IVH), necrotizing enterocolitis, bronchopulmonary dysplasia, periventricular leukomalacia, retinopathy of prematurity, seizure, or neonatal intensive care unit (NICU) admission for $>48$ hours for full-term infant. Diagnosis of neonatal complications was made by the neonatologists at individual participating sites following institutional standardized protocols. Chi-square test was used for analysis of categorical variables and analysis of variance (ANOVA) was used to compare continuous data. Fisher's exact test was used when cells had expected counts less than 5. The Wilcoxon rank-sum test was used to analyze differences in the median GA at diagnosis of PE. Post hoc Tukey's test was performed after ANOVA when indicated. Level of significance was set at $<0.05$. All reported tests of statistical significance were two sided. All analyses were performed with SAS for Windows (version 9.4).

\section{Results}

A total of 675 patients were adjudicated with a final diagnosis of PE by the PETRA's independent panel. Of these, 406 women $(60.1 \%)$ underwent timed 12 or 24 hours urine collections. One-hundred two women $(25.1 \%)$ were classified as nonproteinuria PE, 268 pregnancies (66.0\%) had mildproteinuria $\mathrm{PE}$, and 36 cases $(8.8 \%)$ had massive-proteinuria PE. Baseline demographic and clinical characteristics were similar among the three groups, with the exception of nulliparity which was more prevalent in women with massive-proteinuria PE ( - Table 1). The rate of twin and triplet gestations was low and not significantly different between the PE groups. Mean UP excretion levels in each group are depicted in - Table 1. Massive-proteinuria PE women compared with mild-proteinuria and nonproteinuria PE groups were enrolled at a much earlier GA (median GA $=30.6$ weeks [interquartile range, IQR, 28.2-33.6] vs. 32.4 weeks [IQR, 28.2-33.6] and 32.9 weeks [IQR, 30.4-35.6], respectively, -Table 1; $p=0.002$ ). Mean SBP and DBP within 24 hours of delivery was significantly higher in mass-proteinuria PE pregnancies compared with those with mild and no proteinuria ( $p<0.001$; - Table 1$)$. 
Table 1 Demographic and clinical characteristics of women with PE stratified by protein quantity in urine

\begin{tabular}{|c|c|c|c|c|c|c|c|}
\hline & \multicolumn{2}{|c|}{ Nonproteinuria } & \multicolumn{2}{|c|}{ Mild proteinuria } & \multicolumn{2}{|c|}{$\begin{array}{l}\text { Massive } \\
\text { proteinuria }\end{array}$} & \multirow[t]{2}{*}{$p$-Value } \\
\hline & $N=102$ & $\%$ & $N=268$ & $\%$ & $N=36$ & $\%$ & \\
\hline \multicolumn{8}{|l|}{ Plurality } \\
\hline Singletons & 96 & & 245 & & 32 & & \multirow[t]{4}{*}{0.82} \\
\hline Multiples & 6 & & 23 & & 4 & & \\
\hline Twins & 5 & & 20 & & 2 & & \\
\hline Triplets & 1 & & 3 & & 2 & & \\
\hline \multicolumn{8}{|l|}{ Age $(y)$} \\
\hline $16-24$ & 28 & 27.5 & 90 & 33.6 & 13 & 36.1 & \multirow[t]{3}{*}{0.76} \\
\hline $25-34$ & 54 & 52.9 & 130 & 48.5 & 18 & 50.0 & \\
\hline $35-45$ & 20 & 19.6 & 48 & 17.9 & 5 & 13.9 & \\
\hline \multicolumn{8}{|l|}{ Gravidity } \\
\hline Nulliparous & 53 & 52.0 & 168 & 62.7 & 29 & 80.6 & \multirow[t]{2}{*}{0.003} \\
\hline Multiparous & 49 & 48.0 & 100 & 37.3 & 7 & 19.4 & \\
\hline \multicolumn{8}{|l|}{ Race } \\
\hline White & 58 & 56.9 & 147 & 54.9 & 23 & 63.9 & \multirow[t]{4}{*}{0.70} \\
\hline Black & 30 & 29.4 & 87 & 32.5 & 7 & 19.4 & \\
\hline Asian & 3 & 2.9 & 5 & 1.9 & 1 & 2.8 & \\
\hline Other & 11 & 10.8 & 29 & 10.8 & 5 & 13.9 & \\
\hline Median GA at enrollment (wk; IQR) & \multicolumn{2}{|c|}{$32.9(30.4-35.6)$} & \multicolumn{2}{|c|}{$32.4(29.7-34.9)$} & \multicolumn{2}{|c|}{$30.6(28.2-33.6)$} & $0.002^{\mathrm{a}}$ \\
\hline $\mathrm{BMI} \geq 30$ & 63 & 61.8 & 169 & 63.1 & 21 & 58.3 & 0.94 \\
\hline \multicolumn{8}{|l|}{ Tobacco use } \\
\hline Present & 79 & 77.5 & 227 & 84.7 & 28 & 77.8 & \multirow[t]{2}{*}{0.18} \\
\hline Quit & 23 & 22.5 & 41 & 15.3 & 8 & 22.2 & \\
\hline $\mathrm{H} / \mathrm{O}$ preexisting diabetes & 9 & 8.8 & 14 & 5.2 & 2 & 5.6 & 0.75 \\
\hline $\mathrm{H} / \mathrm{O}$ lupus & 0 & 0 & 2 & 0.7 & 1 & 2.8 & 0.38 \\
\hline $\mathrm{H} / \mathrm{O}$ APS & 0 & 0 & 1 & 0.4 & 0 & 0 & 0.26 \\
\hline $\mathrm{H} / \mathrm{O} \mathrm{PE}$ in a previous gestation & 37 & 36.3 & 77 & 28.7 & 7 & 19.4 & 0.26 \\
\hline Mean SBP ${ }^{\mathrm{b}}$ (mean $\left.\pm \mathrm{SD}\right)$ & \multicolumn{2}{|c|}{$143.3 \pm 12.1$} & \multicolumn{2}{|c|}{$145.7 \pm 11.6$} & \multicolumn{2}{|c|}{$148.3 \pm 8.9$} & $<0.001^{\mathrm{a}}$ \\
\hline Mean $\mathrm{DBP}^{\mathrm{b}}($ mean $\pm \mathrm{SD})$ & \multicolumn{2}{|c|}{$84.2 \pm 8.8$} & \multicolumn{2}{|c|}{$86.7 \pm 7.8$} & \multicolumn{2}{|c|}{$88.6 \pm 8.0$} & $<0.001^{\mathrm{a}}$ \\
\hline Highest SBPC (mean \pm SD) & \multicolumn{2}{|c|}{$168.1 \pm 20.7$} & \multicolumn{2}{|c|}{$171.5 \pm 18.2$} & \multicolumn{2}{|c|}{$175.4 \pm 16.1$} & $0.0008^{d}$ \\
\hline Highest DBP ${ }^{c}($ mean \pm SD) & \multicolumn{2}{|c|}{$101.9 \pm 13.5$} & \multicolumn{2}{|c|}{$103.4 \pm 10.9$} & $108.3 \pm$ & & $0.006^{\mathrm{a}}$ \\
\hline 24-h proteinuria (mg; mean \pm SD) & $162.9 \pm$ & & $1,170 \pm$ & & $9,117 \pm$ & & $0.0001^{\mathrm{e}}$ \\
\hline 12-h proteinuria (mg; mean \pm SD) & $117.0 \pm$ & & $793.9 \pm$ & & $6,015 \pm$ & & $0.0001^{d}$ \\
\hline
\end{tabular}

Abbreviations: APS, antiphospholipid antibody syndrome; BMI, body mass index early in gestation; DBP, diastolic blood pressure; GA, gestational age; H/O, history of; IQR, interquartile range; PE, preeclampsia; SBP, systolic blood pressure; SD, standard deviation.

${ }^{a}$ Significant difference between massive-proteinuria PE and the other PE groups.

${ }^{\mathrm{b}}$ Mean blood pressures within 24 hours before delivery.

'Highest blood pressure before delivery.

${ }^{\mathrm{d}}$ Significant difference between non-proteinuria PE and the other PE groups.

eSignificant difference in all multiple comparisons between the PE groups.

Platelet count and liver enzymes serum levels were similar among the groups. The uric acid levels were higher in the massive-proteinuria PE (median, $6.7 \mathrm{mg} / \mathrm{dL} ; \mathrm{IQR}, 5.5-7.6$ ) compared with the mild-proteinuria PE (median, $5.9 \mathrm{mg} / \mathrm{dL}$; IQR, 4.9-7.0) and nonproteinuria PE (median, $5.1 \mathrm{mg} / \mathrm{dL}$; IQR,
4.3-5.8) groups $(p<0.001$; - Table 2$)$. Uric acid was also significantly higher in the mild-proteinuria PE compared with nonproteinuria PE pregnancies. Among clinical signs and symptoms related to PE ( - Table 3 ), RUQ/epigastric pain was reported in $19.4 \%$ of massive-proteinuria PE women 
Table 2 Laboratory parameters within 24 hours of delivery in the PE subgroups

\begin{tabular}{|c|c|c|c|c|c|c|c|}
\hline & \multicolumn{2}{|c|}{ Nonproteinuria } & \multicolumn{2}{|c|}{ Mild proteinuria } & \multicolumn{2}{|c|}{ Massive proteinuria } & \multirow[t]{2}{*}{$p$-Value } \\
\hline & $N=102$ & Median (IQR) & $N=268$ & Median (IQR) & $N=36$ & Median (IQR) & \\
\hline Platelets $(\mathrm{N} / \mu \mathrm{L})$ & 95 & $\begin{array}{l}207.0 \\
(160.0-258.0)\end{array}$ & 223 & $\begin{array}{l}202.0 \\
(161.0-246.0)\end{array}$ & 33 & $196.0(153.0-228.0)$ & 0.33 \\
\hline AST (U/L) & 87 & $\begin{array}{l}21.0 \\
(17.0-32.0)\end{array}$ & 210 & $\begin{array}{l}21.0 \\
(17.0-31.0)\end{array}$ & 31 & $24.0(20.0-34.0)$ & 0.16 \\
\hline $\operatorname{ALT}(\mathrm{U} / \mathrm{L})$ & 86 & $16.0(12.0-27.0)$ & 205 & $\begin{array}{l}17.0 \\
(12.0-28.0)\end{array}$ & 31 & $18.0(14.0-34.0)$ & 0.54 \\
\hline $\begin{array}{l}\text { Serum creatinine } \\
(\mathrm{mg} / \mathrm{dL})\end{array}$ & 86 & $0.6(0.5-0.7)$ & 210 & $\begin{array}{l}0.6 \\
(0.5-0.7) \\
\end{array}$ & 34 & $0.7(0.6-0.8)$ & $<0.01^{\mathrm{a}}$ \\
\hline Uric acid (mg/dL) & 62 & $5.1(4.3-5.8)$ & 154 & $\begin{array}{l}5.9 \\
(4.9-7.0)\end{array}$ & 22 & $6.7(5.5-7.6)$ & $<0.001^{\mathrm{b}}$ \\
\hline
\end{tabular}

Abbreviations: ALT, alanine aminotransferase; AST, aspartate aminotransferase; IQR, interquartile range; PE, preeclampsia.

${ }^{a}$ Significant difference between massive-proteinuria PE compared with mild-proteinuria PE and nonproteinuria PE.

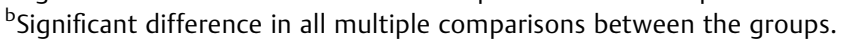

compared with $5.2 \%$ in mild-proteinuria PE and $7.8 \%$ of nonproteinuria PE patients $(p=0.007$; significant difference between mild- and massive-proteinuria PEs). Maternal neurological symptoms did not vary significantly between the $\mathrm{PE}$ subgroups. HELLP syndrome was diagnosed in $2 / 36$ (5.6\%) of massive-proteinuria $\mathrm{PE}$, in $1 / 268(0.4 \%)$ of mild-proteinuria $\mathrm{PE}$, and in $4 / 102(3.9 \%)$ of those with nonproteinuria PE. HELLP syndrome rate was significantly lower in the mildproteinuria PE group compared with the other groups $(p<0.005)$, but similar between nonproteinuria and massive-proteinuria PEs.

There was not a significant difference in either individual or composite adverse maternal morbidity among the PE groups ( - Table 4). Adverse maternal morbidity was uncommon overall, with any element occurring in $<6 \%$ of cases in all three groups. There were no cases of maternal death. Median GA (IQR) at delivery for massive-proteinuria, mildproteinuria, and nonproteinuria PE groups were 31.3 (28.633.6), 34.0 (30.6-36.7), and 36.6 (34.1-38.4) weeks, respectively ( - Table $5 ; p<0.001$ ). Preterm delivery $<34^{0 / 7}$ weeks occurred in $80.6 \%$ of massive-proteinuria PE patients, in $49.3 \%$ of mild-proteinuria PE women, and in $22.5 \%$ of women with nonproteinuria PE $(p<0.0001)$. The difference in the preterm birth rate $<34^{0 / 7}$ weeks between the nonproteinuria and mild-proteinuria PE groups was also significant $(p<0.0001)$. Similar differences were noted in the delivery rate $<37^{0 / 7}$ weeks across all the groups ( - Table 5 ). Cesarean delivery rate was significantly higher in the massive-proteinuria PE (86.1\%) than in the mild-proteinuria PE (64.9\%) and nonproteinuria $\mathrm{PE}(55.9 \%)$ groups $(p=0.0001)$. Stillbirth and IUGR (both, EFW $<10$ th percentile or EFW $<5$ th percentile by ultrasound exam) rates were similar across the groups ( - Table 5). Composite adverse fetal outcome was driven by the significant differences noted in the preterm delivery rates among the groups, with the highest percentages noted, as mentioned earlier, in the massive-proteinuria PE group.

Of our study's 443 neonates, 42 (9.4\%) were born to massive-proteinuria, $292(66.0 \%)$ to mild-proteinuria, and 109 (24.6\%) to nonproteinuria PE women. Mean birth weight was significantly lower in the massive-proteinuria PE neonates $(1,392 \pm 557 \mathrm{~g})$ compared with those born to mildproteinuria $\mathrm{PE} \quad(1,937 \pm 892 \mathrm{~g})$ and nonproteinuria $(2,456 \pm 885 \mathrm{~g})$ PE women $(p<0.001)$. The differences in birth weight were also significant between nonproteinuria and mild-proteinuria PE neonates (-Table 6). Apgar score $<7$ at 5 minutes was reported more commonly in the massive-proteinuria PE infants (19.0\%) than for mild-proteinuria $(7.2 \%)$ and nonproteinuria $(6.4 \%)$ groups, respectively $(p=0.0005)$. Umbilical arterial cord gasses were reported only in 226 of 443 subjects (51.0\%) and there was no difference on the mean $\mathrm{pH}$ or in the number of $\mathrm{pH}$ values $<7.0$ across the groups. RDS was the most common neonatal complication affecting $47.6 \%$ of massive-proteinuria PE, $28.8 \%$ of mild-proteinuria PE, and $11.0 \%$ of non-proteinuria

Table 3 PE-related symptoms between the PE subgroups

\begin{tabular}{|l|l|l|l|l|l|l|l|}
\hline \multirow{2}{*}{} & \multicolumn{2}{|l|}{ Nonproteinuria } & \multicolumn{2}{l|}{ Mild proteinuria } & \multicolumn{2}{l|}{$\begin{array}{l}\text { Massive } \\
\text { proteinuria }\end{array}$} \\
\cline { 2 - 8 } & $\mathrm{N}=\mathbf{1 0 2}$ & $\%$ & $N=\mathbf{2 6 8}$ & $\%$ & $N=36$ & $\%$ & \\
\hline RUQ pain/epigastric pain & 8 & 7.8 & 14 & 5.2 & 7 & 19.4 & $0.007^{\text {a }}$ \\
\hline Headache, visual changes & 34 & 33.3 & 104 & 38.8 & 16 & 44.4 & 0.79 \\
\hline Nausea and vomiting & 8 & 7.8 & 25 & 9.3 & 6 & 16.7 & 0.29 \\
\hline
\end{tabular}

Abbreviations: PE, preeclampsia; RUQ, right upper quadrant.

${ }^{a}$ Significant difference between massive-proteinuria and mild-proteinuria PE groups. 
54 Massive Urinary Protein Excretion in Preeclampsia Mateus et al.

Table 4 Individual and composite adverse maternal outcome in women with PE stratified by protein quantity in urine

\begin{tabular}{|c|c|c|c|c|c|c|c|}
\hline & \multicolumn{2}{|c|}{ Nonproteinuria } & \multicolumn{2}{|c|}{ Mild proteinuria } & \multicolumn{2}{|c|}{$\begin{array}{l}\text { Massive } \\
\text { proteinuria }\end{array}$} & \multirow[t]{2}{*}{$p$-Value } \\
\hline & $N=102$ & $\%$ & $N=268$ & $\%$ & $N=36$ & $\%$ & \\
\hline Acute renal failure & 0 & 0 & 0 & 0 & 1 & 2.8 & 0.094 \\
\hline Liver hematoma/rupture & 0 & 0 & 0 & 0 & 0 & 0 & $\mathrm{~N} / \mathrm{A}$ \\
\hline Acute myocardial infarction & 0 & 0 & 0 & 0 & 0 & 0 & $\mathrm{~N} / \mathrm{A}$ \\
\hline Cortical blindness & 0 & 0 & 0 & 0 & 0 & 0 & $\mathrm{~N} / \mathrm{A}$ \\
\hline Renal detachment & 0 & 0 & 0 & 0 & 0 & 0 & $\mathrm{~N} / \mathrm{A}$ \\
\hline Pulmonary edema/ARDS & 3 & 2.9 & 4 & 1.5 & 1 & 2.8 & 0.06 \\
\hline Placental abruption & 0 & 0 & 5 & 1.9 & 1 & 2.8 & 0.09 \\
\hline Death & 0 & 0 & 0 & 0 & 0 & 0 & $\mathrm{~N} / \mathrm{A}$ \\
\hline Eclampsia & 0 & 0 & 0 & 0 & 1 & 2.8 & 0.09 \\
\hline Third IV antihypertensive agent & 1 & 1.0 & 8 & 3.0 & 0 & 0 & 0.11 \\
\hline DIC & 0 & 0 & 0 & 0 & 1 & 2.8 & 0.09 \\
\hline Composite adverse maternal outcome & 4 & 3.9 & 9 & 3.4 & 2 & 5.6 & 0.70 \\
\hline
\end{tabular}

Abbreviations: ARDS, acute respiratory distress syndrome; DIC, disseminated intravascular disease; IV, intravenous; N/A, not available; PE, preeclampsia.

Note: Fisher's exact tests were used when several cells have expected counts less than 5.

PE newborns ( $p<0.001$; - Table 7). Other individual adverse neonatal outcomes did not differ among the groups. However, composite adverse neonatal outcome, driven mainly by RDS and other prematurity-related complications, was significantly higher in the massive-proteinuria PE than in the other groups ( $p=0.001 ;$ - Table 7 ). There were no neonatal deaths in any group.

\section{Comment}

This prospective cohort study with independent adjudication of PE diagnosis using the new 2013 ACOG criteria indicates that individual and composite adverse maternal outcomes were not increased in preeclamptic women with massive proteinuria compared with those with mild or nonproteinuria PE. However, we found that massive-proteinuria PE was associated with preterm delivery $<34^{0 / 7}$ weeks in more than $80 \%$ of cases, which was almost twice as high as the mild-proteinuria PE group and almost four times higher than in the nonproteinuria group. Women with massiveproteinuria had more PE-related symptoms and laboratory abnormalities including higher BP, RUQ/epigastric pain, and higher uric acid levels suggesting a more severe clinical presentation. Also, enrollment occurred much earlier in women with massive proteinuria indicating that the diagnosis was made at more preterm GAs. This earlier and more

Table 5 Individual and composite adverse fetal outcomes in women with PE stratified by protein quantity in urine

\begin{tabular}{|c|c|c|c|c|c|c|c|}
\hline & Nonproteinuria & & Mild proteinuria & & Massive proteinu & & $p$-Value \\
\hline Pregnancies & $N=102$ & $\%$ & $N=268$ & $\%$ & $N=36$ & $\%$ & \\
\hline Fetuses & $N=109$ & $\%$ & $N=294$ & $\%$ & $N=42$ & $\%$ & \\
\hline $\begin{array}{l}\text { Median GA at delivery } \\
\text { (wk; IQR) }\end{array}$ & $36.6(34.1-38.4)$ & & $34.0(30.6-36.7)$ & & $31.3(28.6-33.6)$ & & $<0.001^{\mathrm{a}}$ \\
\hline Delivery $<34^{0 / 7}$ wk & 23 & 22.5 & 132 & 49.3 & 29 & 80.6 & $<0.0001^{\mathrm{a}}$ \\
\hline Delivery $<37^{0 / 7}$ wk & 66 & 64.7 & 190 & 70.9 & 31 & 86.1 & $0.001^{\mathrm{a}}$ \\
\hline Stillbirth & 0 & 0 & 2 & 0.7 & 0 & 0 & $\mathrm{~N} / \mathrm{A}$ \\
\hline EFW $<10$ th percentile & 11 & 10.1 & 30 & 10.2 & 4 & 9.5 & 0.99 \\
\hline EFW $<$ 5th percentile & 4 & 3.7 & 15 & 5.1 & 2 & 4.8 & 0.83 \\
\hline $\begin{array}{l}\text { Composite adverse fetal } \\
\text { outcome }\end{array}$ & 64 & 58.7 & 228 & 77.6 & 40 & 95.2 & $<0.0001^{\mathrm{a}}$ \\
\hline
\end{tabular}

Abbreviations: EFW, estimated fetal weight; GA, gestational age; IQR, interquartile range; PE, preeclampsia.

a Significant difference noted in all multiple comparisons between the PE groups. 
Table 6 Birth outcomes in PE pregnancies stratified by protein quantity in urine

\begin{tabular}{|c|c|c|c|c|c|c|c|}
\hline & \multicolumn{2}{|c|}{$\begin{array}{l}\text { Nonproteinur- } \\
\text { ia }\end{array}$} & \multicolumn{2}{|c|}{ Mild proteinuria } & \multicolumn{2}{|c|}{$\begin{array}{l}\text { Massive } \\
\text { proteinuria }\end{array}$} & $p$-Value \\
\hline Cesarean delivery, $N(\%)$ & \multicolumn{2}{|c|}{$57(55.9)$} & \multicolumn{2}{|c|}{$174(64.9)$} & \multicolumn{2}{|c|}{$31(86.1)$} & $0.0001^{\mathrm{a}}$ \\
\hline Birth weight $(\mathrm{g}$; mean \pm SD) & \multicolumn{2}{|c|}{$2,456 \pm 885.3$} & \multicolumn{2}{|c|}{$1,937 \pm 892.8$} & \multicolumn{2}{|c|}{$1,392 \pm 557.0$} & $<0.001^{a}$ \\
\hline Neonatal gender & $N$ & $\%$ & $N$ & $\%$ & $N$ & $\%$ & \\
\hline Female & 61 & 56.0 & 162 & 55.5 & 24 & 57.1 & \multirow[t]{2}{*}{0.60} \\
\hline Male & 48 & 44.0 & 130 & 44.2 & 18 & 42.9 & \\
\hline Apgar score $<7$ at 5 min & 7 & 6.4 & 21 & 7.2 & 8 & 19.0 & $0.0005^{\mathrm{b}}$ \\
\hline Umbilical cord arterial $\mathrm{pH}<7.0^{\mathrm{c}}$ & 1 & 0.9 & 1 & 0.3 & 0 & 0 & 0.40 \\
\hline
\end{tabular}

Abbreviations: GA, gestational age; PE, preeclampsia; SD, standard deviation. aSignificant difference in all multiple comparisons between the PE groups.

${ }^{\mathrm{b}}$ Significant difference between massive-proteinuria and the other PE groups.

${ }^{\mathrm{C}}$ Data available in 226 cases.

severe presentation certainly influenced the clinical management and the final decision for delivery. The higher neonatal morbidity rate seen in infants born to massiveproteinuria women was most likely related to the earlier GA at delivery with RDS being the most common neonatal complication affecting almost half of these infants. The cesarean delivery rate was extremely high $(86.1 \%)$ in the massive-proteinuria PE group and $19 \%$ of newborns from this group had Apgar scores $<7$ at 5 minutes. Although we did not analyze fetal testing data, our results suggest the possibility that compromise of the fetal condition played a major role in the mode and timing of delivery in these patients. IUGR, defined as EFW < 10th percentile, occurred in 9.5 to $10.2 \%$ of the enrolled pregnancies without significant differences among the groups.

Several studies have shown that the presence of proteinuria in PE increases the risk for specific adverse pregnancy outcomes. ${ }^{21-25}$ Using a different proteinuria threshold from our study, a recent secondary analysis of the Vitamins in PE (VIP) trial found that preeclamptic pregnancies with a timed 24-hour proteinuria $\geq 500 \mathrm{mg}$ compared with 300 to $499 \mathrm{mg}$ delivered significantly earlier (33.2 vs. 37.2 weeks) and had a significantly higher cesarean delivery rate (78 vs. $48 \%$ ). ${ }^{21}$ In the VIP trial, preterm delivery $<34$ weeks occurred more often in the group with greater proteinuria (26.7 vs. $13.3 \%)$. Two prospective cohorts have shown that the presence of proteinuria, defined as UP/CR $\geq 30 \mathrm{mg} / \mathrm{mmol},{ }^{25}$ or $>300 \mathrm{mg}$ in 24 hours, ${ }^{22,25}$ compared with nonproteinuria in preeclamptic pregnancies is associated with both increased maternal and fetal complications such as hyperuricemia, severe hypertension, renal insufficiency, thrombocytopenia, liver disease, preterm delivery $<37^{0 / 7}$ weeks, perinatal mortality, and SGA. ${ }^{22,25}$ Other investigators have found that elevated UP excretion assessed by spot UP/CR ( $\geq$ $0.3 \mathrm{mg} / \mathrm{mg}$ ) also predisposes to adverse maternal and perinatal outcomes including severe maternal hypertension,

Table 7 Individual and composite adverse neonatal outcome in women with PE stratified by protein quantity in urine

\begin{tabular}{|c|c|c|c|c|c|c|c|}
\hline \multirow[t]{2}{*}{$N=443$} & \multicolumn{2}{|c|}{ Nonproteinuria } & \multicolumn{2}{|c|}{ Mild proteinuria } & \multicolumn{2}{|c|}{$\begin{array}{l}\text { Massive } \\
\text { proteinuria }\end{array}$} & \multirow[t]{2}{*}{$p$-Value } \\
\hline & $N=109$ & $\%$ & $N=292$ & $\%$ & $N=42$ & $\%$ & \\
\hline Respiratory distress syndrome & 12 & 11.0 & 84 & 28.8 & 20 & 47.6 & $<0.001^{a}$ \\
\hline Intraventricular hemorrhage ${ }^{\mathrm{b}}$ & 3 & 2.8 & 13 & 4.5 & 3 & 7.1 & 0.44 \\
\hline Necrotizing enterocolitis & 1 & 0.9 & 4 & 1.4 & 0 & 0 & 0.72 \\
\hline Bronchopulmonary dysplasiab & 0 & 0 & 2 & 0.7 & 2 & 4.8 & 0.10 \\
\hline Periventricular leucomalacia & 0 & 0 & 0 & 0 & 0 & 0 & $\mathrm{~N} / \mathrm{A}$ \\
\hline Retinopathy of prematurity ${ }^{b}$ & 2 & 1.8 & 7 & 2.4 & 4 & 9.5 & 0.10 \\
\hline Seizure & 0 & 0 & 0 & 0 & 0 & 0 & $\mathrm{~N} / \mathrm{A}$ \\
\hline NICU admission $>48 \mathrm{~h}$ for full-term infant & 2 & 1.8 & 0 & 0 & 0 & 0 & $\mathrm{~N} / \mathrm{A}$ \\
\hline Neonatal death & 0 & 0 & 0 & 0 & 0 & 0 & $\mathrm{~N} / \mathrm{A}$ \\
\hline Composite adverse neonatal outcome & 17 & 15.6 & 94 & 32.0 & 21 & 50.0 & $0.001^{\mathrm{a}}$ \\
\hline
\end{tabular}

Abbreviations: N/A, not available; NICU, neonatal intensive care unit; PE, preeclampsia..

${ }^{\text {a }}$ Significant difference in all multiple comparisons between the PE groups.

'Fisher's exact tests were used when several cells have expected counts less than 5 . 
increased liver enzymes, neurological symptoms, admission to intensive care unit, eclampsia, cesarean delivery, preterm birth, and low birth weight. ${ }^{23,24}$ One of these studies showed that high maternal UP/CR was also associated with low Apgar scores and perinatal death. ${ }^{23}$ Recent multicenter prospective studies conducted in low- and middle-income countries have developed and validated clinical prediction models for adverse maternal outcomes and perinatal death among pregnancies with hypertensive disorders (miniPIERS [Preeclampsia Integrated Estimate of Risk]). In those studies, dipstick proteinuria was included in the models as one of the predictors for these adverse outcomes. ${ }^{28,29}$

Conversely, other evidence does not support the association between proteinuria and adverse pregnancy outcomes. $^{15-20}$ The most comprehensive study is a systematic review of 16 primary studies conducted in $2009 .^{18}$ This systematic review showed that proteinuria was not associated with eclampsia, abruption, or HELLP syndrome, neonatal death, perinatal death, SGA, or NICU admission. Only the stillbirth rate was found to be higher in pregnancies with heavy proteinuria (positive likelihood ratio, 2.0; 95\% confidence interval, 1.5-2.7). That systematic review, however, did not report associations with other important adverse outcomes such as preterm birth rate and neonatal morbidity. Importantly, 5 of the 16 studies (31.2\%) were retrospective and proteinuria quantification was performed by dipstick also in 5 studies. Other limitations included heterogeneity among the studies in regard to study population, definition of PE, and proteinuria thresholds.

One retrospective cohort included in the systematic review had a similar design to our study. ${ }^{15}$ Perinatal outcomes were compared between preeclamptic pregnancies with 24hour proteinuria $<5,5$ to 9.9 , and $\geq 10 \mathrm{~g}$. This study reported that maternal outcomes did not differ between the PE subgroups. The authors found that compared with women with the lesser amounts of proteinuria ( $<5 \mathrm{~g} / 24$ hours), those women with $\geq 10 \mathrm{~g}$ proteinuria were diagnosed earlier (30.6 \pm 3.3 vs. $32.3 \pm 3.4$ weeks $)$ and had earlier deliveries $(30.9 \pm 3.3$ vs. $33.0 \pm 3.2$ weeks $)$. Neonatal complications, that is, RDS and IVH were more common in infants born to mothers with $\geq 10 \mathrm{~g} / 24$ hours of proteinuria compared with the other subsets of patients, but the difference was not statistically different.

Clinical management of enrolled patients was dictated by institutional standardized protocols of participating centers and the final decision for delivery was made considering the global maternal and fetal condition. Composite adverse maternal outcome occurred in the range of 3 to $6 \%$ of all pregnancies and it was similar across the PE groups. Adherence to clinical protocols including prompt delivery in tertiary centers likely explains the low rate of serious adverse maternal outcomes, stillbirth, and neonatal mortality in this cohort. Massive UP excretion $>2.7 \mathrm{~g}$ in 12 hours or $>5 \mathrm{~g}$ in 24 hours was highly prevalent in pregnancies with early onset of PE $<34$ weeks, a variety of PE typically associated with the greatest maternal and perinatal risk. Current clinical obstetrical guidelines in the United States and Canada recommend the exclusion of massive proteinuria
$>5 \mathrm{~g} / 24$ hours $^{14,30}$ as a marker of clinical severity and delivery $<37^{0 / 7}$ weeks is not indicated if this is the only detected abnormality. This may be reasonable if massive proteinuria is an isolated finding; however, it is frequently associated with other clinical manifestations and laboratory abnormalities indicative of greater disease severity and a higher rate of specific adverse pregnancy outcomes.

Exclusion of massive proteinuria from the diagnostic criteria of severe PE could erroneously lead clinicians to believe that these pregnancies have a low rate of complications and better outcomes than those now categorized as PE with "severe features."14,30 In fact, our subgroup of nonproteinuria PE defined by current ACOG clinical and laboratory parameters as having severe features had the most favorable pregnancy outcomes among the studied groups. The median GA at delivery in this group was more than 4 weeks later than in the massive-proteinuria PE group, the mean birth weight was significantly higher, and the rates of cesarean delivery and neonatal complications were much lower. Although no longer part of the clinical criteria for diagnosis, our investigation supports assessment for and observatory vigilance of pregnancies with massive proteinuria. In deciding to undertake expectant management for these pregnancies, the clinician should closely follow a clinical protocol such as the one outlined in the committee opinion of the Society for Maternal-Fetal Medicine. ${ }^{31}$

Our data emphasize the limitations of current and past classifications of PE. The complexity of the disease makes it very challenging to categorize as less or more severe in the ample clinical spectrum. Until we develop a more accurate ancillary test that improves our ability to diagnose PE and predict its outcomes, we should not overlook pregnancies with massive proteinuria even if it is no longer considered a component of the diagnostic criteria for severe PE.

The small sample size of the massive-proteinuria PE group is a major limitation of our study. In the original cohort, proteinuria was measured by different methods including urine dipstick, UP/CR, and timed 12 and 24 hours urine collections. Although all possess accuracy limitations, the latter has been considered the "gold standard" test for several decades. Several studies have reported that the amount of proteinuria collected in a shorter period of time (12 hours) correlates well with the standard 24 hours urine collection. ${ }^{26,27}$ We selected these two methods, as they were considered the most accurate tests available for the quantification of proteinuria. Unfortunately, only 406 of the 675 women diagnosed with PE underwent either of these tests. Our small sample size increases the probability of type II error in some of our statistical analysis. This is particularly true for the relatively rare but life-threatening maternal complications of PE. Also, the small number of cases with massive proteinuria limits our ability to perform additional analysis that might identify a proteinuria threshold at which adverse pregnancy outcomes could become significantly more likely. Although, an independent panel of experts made the diagnosis of PE using current clinical guidelines in the United States, we cannot exclude the possibility of selection bias in this cohort. Relevant clinical data such as 
fetal testing results prior to delivery were not available for analysis limiting our capacity for explaining the high rate of preterm birth, cesarean delivery, and high frequency of low Apgar score in the massive-proteinuria PE group. Furthermore, umbilical cord gasses were only obtained in approximately half of the neonates.

In summary, our investigation found that massive proteinuria occurs frequently in preeclamptic pregnancies diagnosed at early GAs and is often associated with more severe maternal and laboratory abnormalities. We believe that quantification of maternal proteinuria by some method should continue to be part of the clinical evaluation of PE. Importantly, massive proteinuria is unlikely to be an isolated finding. When present, a judicious clinical assessment for the presence of other severe clinical features is justified. While some may argue that quantification of proteinuria is an insufficient predictor of severity and may have resulted in unnecessary early preterm birth, we believe this is unlikely. This cohort demonstrates the association of massive proteinuria with earlier disease onset, severe BP elevations, more frequent laboratory abnormalities, severe maternal symptoms, low Apgar scores, and a higher cesarean delivery rate suggesting that it is a covariable indicating maternal/fetal severity rather than a confounding variable. We encourage the clinician to consider the implications that massive proteinuria has in the clinical course and outcome of PE.

\section{Acknowledgments}

The study group that participated in the PETRA study was Robert Ball, MD, Maternal Fetal Services of Utah, Salt Lake City, UT; Cynthia Gyamfi, MD, Columbia University Medical Center, New York, NY; Christopher Robinson, MD, Medical University of South Carolina, Charleston, SC; Roger Newman, MD, Medical University of South Carolina, Charleston, SC; Bruce Levine, MD, Virtua Phoenix OB-GYN, Moorestown, NJ; Helen How, MD, Norton Healthcare, Louisville, KY; Rovena Reagan, MD, Women's Healthcare, San Diego, CA; Peter von Dadelszen, MD, BC Women's Hospital and Health Centre, Vancouver, BC, Canada; Angela Ranzini, MD, Saint Peter's University Hospital, New Brunswick, NJ; John R. Barton, MD, Central Baptist Hospital, Lexington, KY; C. Andrew Combs, MD, PhD, Obstetrix Medical Group, San Jose, CA; Lara A. Friel, MD, PhD, University of Texas Health Sciences Center, Houston, TX; Douglas A. Woelkers, MD, University of California San Diego, San Diego, CA; Baha M. Sibai, MD, University of Texas Health Sciences Center, Houston, TX.

\section{References}

1 Wallis AB, Saftlas AF, Hsia J, Atrash HK. Secular trends in the rates of preeclampsia, eclampsia, and gestational hypertension, United States, 1987-2004. Am J Hypertens 2008;21(05):521-526

2 Ananth CV, Vintzileos AM. Maternal-fetal conditions necessitating a medical intervention resulting in preterm birth. Am J Obstet Gynecol 2006;195(06):1557-1563
3 Kim SY, Dietz PM, England L, Morrow B, Callaghan WM. Trends in pre-pregnancy obesity in nine states, 1993-2003. Obesity (Silver Spring) 2007;15(04):986-993

4 Ogden CL, Carroll MD, Curtin LR, McDowell MA, Tabak CJ, Flegal KM. Prevalence of overweight and obesity in the United States, 1999-2004. JAMA 2006;295(13):1549-1555

5 Catov JM, Ness RB, Kip KE, Olsen J. Risk of early or severe preeclampsia related to pre-existing conditions. Int J Epidemiol 2007;36(02):412-419

6 Hamilton BE, Miniño AM, Martin JA, Kochanek KD, Strobino DM, Guyer B. Annual summary of vital statistics: 2005. Pediatrics 2007;119(02):345-360

7 Bellamy L, Casas J-P, Hingorani AD, Williams DJ. Pre-eclampsia and risk of cardiovascular disease and cancer in later life: systematic review and meta-analysis. BMJ 2007;335(7627):974

8 McDonald SD, Malinowski A, Zhou Q Yusuf S, Devereaux PJ. Cardiovascular sequelae of preeclampsia/eclampsia: a systematic review and meta-analyses. Am Heart J 2008;156(05):918-930

9 Brown MC, Best KE, Pearce MS, Waugh J, Robson SC, Bell R. Cardiovascular disease risk in women with pre-eclampsia: systematic review and meta-analysis. Eur J Epidemiol 2013;28(01): $1-19$

10 Lewandowski AJ, Leeson P. Preeclampsia, prematurity and cardiovascular health in adult life. Early Hum Dev 2014;90(11): 725-729

11 Lazdam M, de la Horra A, Diesch J, et al. Unique blood pressure characteristics in mother and offspring after early onset preeclampsia. Hypertension 2012;60(05):1338-1345

12 ACOG Committee on Practice Bulletins-Obstetrics. ACOG practice bulletin. Diagnosis and management of preeclampsia and eclampsia. Number 33, January 2002. Obstet Gynecol 2002 99(01):159-167

13 Report of the National High Blood Pressure Education Program Working Group on high blood pressure in pregnancy. Am J Obstet Gynecol 2000;183(01):S1-S22

14 American College of Obstetricians and Gynecologists; Task Force on Hypertension in Pregnancy. Hypertension in pregnancy. Report of the American College of Obstetricians and Gynecologists' Task Force on Hypertension in Pregnancy. Obstet Gynecol 2013; 122(05):1122-1131

15 Newman MG, Robichaux AG, Stedman CM, et al. Perinatal outcomes in preeclampsia that is complicated by massive proteinuria. Am J Obstet Gynecol 2003;188(01):264-268

16 Zhang J, Klebanoff MA, Roberts JM. Prediction of adverse outcomes by common definitions of hypertension in pregnancy. Obstet Gynecol 2001;97(02):261-267

17 Nischintha S, Pallavee P, Ghose S. Correlation between 24-h urine protein, spot urine protein/creatinine ratio, and serum uric acid and their association with fetomaternal outcomes in preeclamptic women. J Nat Sci Biol Med 2014;5(02):255-260

18 Thangaratinam S, Coomarasamy A, O'Mahony F, et al. Estimation of proteinuria as a predictor of complications of pre-eclampsia: a systematic review. BMC Med 2009;7:10

19 Buchbinder A, Sibai BM, Caritis S, et al; National Institute of Child Health and Human Development Network of Maternal-Fetal Medicine Units. Adverse perinatal outcomes are significantly higher in severe gestational hypertension than in mild preeclampsia. Am J Obstet Gynecol 2002;186(01):66-71

20 Hall DR, Odendaal HJ, Steyn DW, Grové D. Urinary protein excretion and expectant management of early onset, severe preeclampsia. Int J Gynaecol Obstet 2002;77(01):1-6

21 Bramham K, Poli-de-Figueiredo CE, Seed PT, et al. Association of proteinuria threshold in pre-eclampsia with maternal and perinatal outcomes: a nested case control cohort of high risk women. PLoS One 2013;8(10):e76083

22 Brown MA, Buddle ML. Hypertension in pregnancy: maternal and fetal outcomes according to laboratory and clinical features. Med J Aust 1996;165(07):360-365 
23 Kumari A, Chakrawarty A, Singh A, Singh R. Maternofoetal complications and their association with proteinuria in a tertiary care hospital of a developing country. J Pregnancy 2014; 2014:431837

24 Chan P, Brown M, Simpson JM, Davis G. Proteinuria in preeclampsia: how much matters? BJOG 2005;112(03):280-285

25 Homer CS, Brown MA, Mangos G, Davis GK. Non-proteinuric preeclampsia: a novel risk indicator in women with gestational hypertension. J Hypertens 2008;26(02):295-302

26 Rinehart BK, Terrone DA, Larmon JE, Perry KG Jr, Martin RW, Martin JN Jr. A 12-hour urine collection accurately assesses proteinuria in the hospitalized hypertensive gravida. J Perinatol 1999;19(8 Pt 1):556-558

27 Adelberg AM, Miller J, Doerzbacher M, Lambers DS. Correlation of quantitative protein measurements in 8-, 12-, and 24-hour urine samples for the diagnosis of preeclampsia. Am J Obstet Gynecol $2001 ; 185(04): 804-807$
28 Payne BA, Hutcheon JA, Ansermino JM, et al; miniPIERS Study Working Group. A risk prediction model for the assessment and triage of women with hypertensive disorders of pregnancy in low-resourced settings: the miniPIERS (Pre-eclampsia Integrated Estimate of RiSk) multi-country prospective cohort study. PLoS Med 2014;11(01):e1001589

29 Payne BA, Groen H, Ukah UV, et al; miniPIERS working group. Development and internal validation of a multivariable model to predict perinatal death in pregnancy hypertension. Pregnancy Hypertens 2015;5(04):315-321

30 Magee LA, Pels A, Helewa M, Rey E, von Dadelszen P; SOGC Hypertension Guideline Committee. Diagnosis, evaluation, and management of the hypertensive disorders of pregnancy: executive summary. J Obstet Gynaecol Can 2014;36(07):575-576

31 Sibai BM; Publications Committee, Society for Maternal-Fetal Medicine. Evaluation and management of severe preeclampsia before 34 weeks' gestation. Am J Obstet Gynecol 2011;205(03):191-198 